\title{
Non-Diabetic Hyperglycemia in the Pediatric Age: Why, How, and When to Treat?
}

\author{
Valentina Fattorusso $^{1} \cdot$ Rosa Nugnes $^{1} \cdot$ Alberto Casertano $^{1} \cdot$ Giuliana Valerio $^{2} \cdot$ Enza Mozzillo $^{1} \cdot$ Adriana Franzese $^{1}$
}

Published online: 29 October 2018

(C) Springer Science+Business Media, LLC, part of Springer Nature 2018

\begin{abstract}
Purpose of review Non-diabetic hyperglycemia (NDHY) is a pathological condition that is not yet well known. The aim of this review is to examine approaches for management of this condition.

Recent findings While it is well known that persistent hyperglycemia in diabetes affects immune response and risk for diabetesrelated micro- and macrovascular complications, little is known about the biological effects of transient NDHY, particularly in the pediatric age group.

Summary Stress HY (SHY) is typically defined as blood glucose $>8.33 \mathrm{mmol} / \mathrm{L}(150 \mathrm{mg} / \mathrm{dL})$ during physical stress, resolving spontaneously after dissipation of acute illness in patients without known diabetes. Based on the literature and clinical practice, two situations can be classified: (1) SHY1, which occurs during severe and prolonged illness and under serious life-threatening conditions, mainly in emergency situations and in resuscitation areas; and (2) SHY2, which occurs during acute illness, mainly in non-life-threatening conditions. Furthermore, (NDHY) among pediatric patients can be induced by drugs; the most frequent conditions are secondary to (1) steroid therapy and (2) antineoplastic/immunosuppressive therapy.
\end{abstract}

Keywords Non-diabetic hyperglycemia $\cdot$ Stress hyperglycemia $\cdot$ Drug-induced hyperglycemia $\cdot$ Management

This article is part of the Topical Collection on Pediatric Type 2 and Monogenic Diabetes

Enza Mozzillo

mozzilloenza@gmail.com

Valentina Fattorusso

vfattorusso1@gmail.com

Rosa Nugnes

rosanugnes@gmail.com

Alberto Casertano

casertanoalberto@gmail.com

Giuliana Valerio

giuliana.valerio@uniparthenope.it

Adriana Franzese

franzese@unina.it

1 Department of Translational Medical Science (DISMET), Section of Pediatrics, University of Naples Federico II, Naples, Italy

2 Department of Movement Sciences and Wellbeing, Parthenope University, Naples, Italy

\section{Introduction}

Non-diabetic hyperglycemia (NDHY) is a pathological condition that it is not due to chronic insulinopenia or chronic insulin resistance. The impact of NDHY needs to be better understood. While it is well known that persistent $\mathrm{HY}$ in diabetes affects immune defenses and produces endothelial damage and degenerative oxide-reduction processes, little is known about the biological effects of non-diabetic and non-persistent HY, particularly in the pediatric age population, and validated protocols for managing this condition are completely lacking.

Stress HY (SHY) is typically defined as glucose levels > $8.33 \mathrm{mmol} / \mathrm{L}$ (> $150 \mathrm{mg} / \mathrm{dL}$ ) occurring as a response to stress, and resolving spontaneously after dissipation of acute illness in patients without known diabetes [1, 2]. Based on the literature and clinical practice, two situations can be described: (1) SHY1, which occurs during severe and prolonged illness and during serious life-threatening situations, primarily in emergency departments and resuscitation areas; and (2) SHY2, which occurs during acute illness, largely in non-lifethreatening situations. Furthermore, NDHY in pediatric patients can be induced by drugs, with the most frequent 
conditions secondary to (1) steroid therapy and (2) antineoplastic/immunosuppressive therapy.

\section{SHY1: Severe and Prolonged Illness}

Several studies have suggested that patients with SHY1 under resuscitation conditions and with no previous diagnosis of diabetes are at higher risk of adverse consequences [1-8]. An estimated $49-72 \%$ of critically ill children experience blood glucose levels $>8.3 \mathrm{mmol} / \mathrm{L}(>150 \mathrm{mg} / \mathrm{dL})$, while $20-35 \%$ have values $>11.11 \mathrm{mmol} / \mathrm{L}(>200 \mathrm{mg} / \mathrm{dL})$. In adults, SHY and glucose variability are associated with increased morbidity and mortality. Similarly, studies in children have shown that SHY during critical illness is associated with poor outcomes; higher values and duration appear to be associated with increased mortality [2]. Such association has been reported in cases of septic shock, burns, traumatic brain injury, postcardiac surgery, and trauma. Additionally, SHY in critically ill children is associated with longer periods of intensive care unit (ICU) and hospital stay and more frequent nosocomial infections, including surgical site infections [1]. Although several studies have demonstrated a strong correlation between SHY1 and poor clinical outcomes, they do not necessarily demonstrate a cause-effect relationship, because SHY tends to be more marked in patients with greater illness severity $[9-13,14 \cdot \bullet]$. However, it is certainly not known whether surviving SHY1 patients are prone to future development of glucose metabolism derangement. Moradi et al. [15] demonstrated a significant relationship between SHY1 and the development of diabetes mellitus (DM) among 98 adult patients referred to the emergency room due to trauma, myocardial infarction, subarachnoid hemorrhage, head trauma, sepsis, or abdominal surgery: $8 \%$ developed DM and 26\% developed prediabetes.

\section{SHY2: Acute Non-Severe IIIness}

Valerio et al. described greater prevalence of SHY2 in children (mean age $5.2 \pm 4.5$ years) affected by febrile convulsions or traumatic injury (12.9 and $11.7 \%$, respectively, vs. $2.2 \%$ in patients presenting only with fever), underscoring the higher frequency among the very young [16]. In this work, two groups of children were studied: 833 children admitted to the care center for acute illness or injury constituted the stress-exposed group, while 366 children admitted for elective minor surgery represented the stress-unexposed group and served as the control group. SHY2, which was defined as plasma glucose values $\geq 8.3 \mathrm{mmol} / \mathrm{L}(\geq 150 \mathrm{mg} / \mathrm{dL})$ during acute illness, was found in 41 (4.9\%) stress-exposed patients and in none of the controls. A significant correlation was observed between glycemia and systolic pressure, white cell count, and body temperature. SHY2 was more frequent in patients with body temperature $>39 \mathrm{C}^{\circ}$ and more prevalent in those with fever associated with seizures or pain than with fever alone. After a mean follow-up period of $3.5 \pm 0.6$ years, none of the hyperglycemic patients developed DM. Mobaireek et al. found $\mathrm{HY} \geq 11.1 \mathrm{mmol} / \mathrm{L}(200 \mathrm{mg} / \mathrm{dL})$ in $38.6 \%$ of children (mean age $5.4 \pm 2.6$ years) with acute asthma, and concluded that blood glucose level was associated with the length of hospitalization, with a median extension of 1.8 days [17]. Weiss et al. [18] reviewed a cohort of 55,120 patients referred to the emergency room, most commonly due to respiratory illness, trauma, or seizure, and found that extreme SHY (glucose $>16.7 \mathrm{mmol} / \mathrm{L}$, or $300 \mathrm{mg} / \mathrm{dL}$ ) occurred at a rate of $0.13 \%$. The authors reported a spontaneous drop in glycemia to the threshold of $8.3 \mathrm{mmol} / \mathrm{L}(150 \mathrm{mg} /$ $\mathrm{dL}$ ) within 2 days; for this reason they suggest that SHY should not be treated with insulin but only with hydration.

As in the case of SHY1, it is not clear whether SHY2 patients are prone to developing glucose metabolism derangement. Weiss et al. found no increased risk of developing diabetes among SHY2 patients, but the authors encourage further study [18].

\section{SHY Management}

Various studies have explored the effectiveness of treatments in patients with severe critical illness, particularly among adults and in children after cardiac surgery. Vlasselaers et al. studied 700 children aged $0-16$ years admitted to the ICU, who were randomly assigned to either conventional (continuous insulin infusion started for blood glucose values $>11.9 \mathrm{mmol} / \mathrm{L}[214$ $\mathrm{mg} / \mathrm{dL}]$ and stopped for blood glucose values $<10.0 \mathrm{mmol} / \mathrm{L}$ $[180 \mathrm{mg} / \mathrm{dL}]$ ) or intensive insulin therapy (continuous insulin infusion to target age-adjusted normoglycemia). The second group had shorter ICU stay, attenuated inflammatory response, and lower mortality, but a substantial increase in hypoglycemic episodes, compared with the conventional group [19]. Agus et al. [20] studied 980 children aged 0-36 months undergoing cardiac surgery, randomly assigned to either tight glycemic control, targeting blood glucose of 4.4-6.1 mmol/L (79-110 $\mathrm{mg} / \mathrm{dL}$ ), or standard care without insulin therapy; the first group had a higher rate of hypoglycemia, but no significant difference in morbidity or mortality. Jeschke et al. [21] investigated 239 children aged $2.5-15$ years affected by burns over $>30 \%$ of their total body surface area, who were randomly assigned to either intensive (blood glucose target of 4.44 $6.11 \mathrm{mmol} / \mathrm{L}$ [79-110 mg/dL]) or control group (blood glucose target of $7.78-10 \mathrm{mmol} / \mathrm{L}$ ); patients in the first group had a significantly lower incidence of infections and higher incidence of hypoglycemia. Another study [22] explored the benefits and risks of intensive therapy in 3288 critically ill children described in four randomized controlled trials (RCTs), and concluded that intensive insulin therapy resulted in fewer 
infections, but a higher incidence of hypoglycemia. Pham et al. [23] retrospectively observed that intensive insulin treatment in 33 children with severe burns was associated with lower rates of infection and improved survival compared to 31 conventionally treated controls. Macrae et al. [24] found that intensive insulin treatment in 1369 critically ill children from 13 centers did not lead to improvement in the primary endpoint of freedom from mechanical ventilation at 30 days, but did shorten hospital stay in one subgroup, and resulted in increased incidence of hypoglycemia. A study by Agus et al. [25], which included 713 critically ill children with confirmed hyperglycemia across 32 centers, failed to demonstrate significant differences in mortality, severity of organ dysfunction, or the number of ventilator-free days between patients with glucose levels maintained at $4.44-6.11 \mathrm{mmol} / \mathrm{L}$ and those maintained at $8.33-10 \mathrm{mmol} / \mathrm{L}$ by continuous glucose monitoring using insulin therapy (Table 1).

Correction of severe hyperglycemia during illness appears to reduce morbidity and mortality; however, the practice of strict glycemic control using insulin therapy remains controversial, and evidence-based guidelines for the treatment of stress hyperglycemia in children without diabetes are still lacking. Further studies are needed to answer important questions including the timing of initiation of insulin therapy, optimal target blood glucose, target population, and most effective protocol for avoiding hypoglycemia.

There are no randomized studies on SHY2 conditions.

\section{Drug-Induced Hyperglycemia}

Several drugs can induce transient or chronic HY, including pentamidine, nicotinic acid, glucocorticoids, thyroid hormone, diazoxide, beta-adrenergic agonists, growth hormone, thiazides, phenytoin, antineoplastic/immunosuppressive drugs, and alfa-interferon, among others.

We focus on two main conditions of HY: HY induced by glucocorticoids (GCS) and HY induced by antineoplastic/ immunosuppressive drugs, probably most frequent in pediatric age groups.

\section{HY Induced by GCS}

It is well known that GCS can impair glucose tolerance, mainly by inducing insulin resistance, and that the effects seem to be dose-dependent [26, 27]. In addition, a possible causal role in direct beta-cell dysfunction has been suggested [28]. In adults,

Table 1 Studies on severe clinical conditions in childhood

\begin{tabular}{|c|c|c|c|c|c|c|}
\hline & Disease & $\begin{array}{l}\text { Number of } \\
\text { Children }\end{array}$ & $\begin{array}{l}\text { Age } \\
\text { (years) }\end{array}$ & $\begin{array}{l}\text { Number of } \\
\text { IIT patients }\end{array}$ & $\begin{array}{l}\text { Hypoglycemia } \\
\text { (IIT vs. CTG) }\end{array}$ & Outcomes IIT \\
\hline $\begin{array}{l}\text { Vlasselaers } \\
\qquad(2009)[19]\end{array}$ & $\begin{array}{l}\text { Critically ill patients } \\
\text { admitted to ICU }\end{array}$ & 700 & $0-16$ & 349 & $\begin{array}{c}25 \text { vs. } 1 \%(p<0.0001 \\
\text { BG }<2.2 \mathrm{mmol} / \mathrm{L}) \\
5 \text { vs. } 1 \%(p=0.001 \\
\text { BG }<1.7 \mathrm{mmol} / \mathrm{L})\end{array}$ & $\begin{array}{l}\text { ICU stay } \Downarrow(5.5 \text { vs. } 6.1 \text { days } p=0.01) \text {. } \\
\text { CRP } \Downarrow(-9.7 \text { vs. } 8.9 \mathrm{mg} /, p=0.007) \text {. } \\
\text { Mortality } \Downarrow(3 \text { vs. } 6 \% ; \mathrm{p}=0.03)\end{array}$ \\
\hline Agus (2012) [20] & $\begin{array}{l}\text { Surgery with cardiopulmonary } \\
\text { bypass }\end{array}$ & 980 & $0-3$ & 490 & $\begin{array}{l}3 \text { vs. } 1 \%(p=0.03 ; \\
\quad \mathrm{BG}<2.2 \mathrm{mmol} / \mathrm{L})\end{array}$ & $\begin{array}{l}\text { No differences: infections, mortality, } \\
\text { ICU stay, mechanical ventilation } \\
\text { and vasoactive support. }\end{array}$ \\
\hline Jeschke (2010) [21] & Burns & 208 & $3-15$ & 60 & $\mathrm{NE}$ & $\begin{array}{l}\text { Infections, sepsis, and MOF } \Downarrow,(p<0.05) \text {. } \\
\text { Mortality } \Downarrow(0 \text { vs. } 12 \% ; p<0.05) \\
\text { Inflammation } \Downarrow \text { (IFN- } \gamma, \text { IL-10, IL-7, } \\
\text { IL-8, IL-5, IL-6, MCP-1; } p<0.05) \\
\text { ALT, AST, total bilirubin, total protein, } \\
\text { BUN and creatinine } \Downarrow(p<0.05)\end{array}$ \\
\hline Pham (2005) [23] & Burns & 64 & $1-11$ & 33 & $\begin{array}{l}27 \text { vs. } 0 \% \\
\quad(B G<2.78 \mathrm{mmol} / \mathrm{L})\end{array}$ & $\begin{array}{l}\text { Urinary tract infections } \Downarrow(0.006 \\
\quad \text { vs. } 0.017 ; p<0.05) \\
\text { Mortality rate } \Downarrow(\mathrm{OR} 4.09 ; p<0.05)\end{array}$ \\
\hline Macrae (2014) [24] & $\begin{array}{l}\text { Critically ill patients } \\
\text { admitted to ICU }\end{array}$ & 1369 & $0-16$ & 694 & $\begin{array}{l}7.3 \text { vs. } 1.5 \%(p<0.001 \\
\text { BG }<2.0 \mathrm{mmol} / \mathrm{L})\end{array}$ & $\begin{array}{l}\text { Mortality rate } \Downarrow \\
\text { Renal-replacement therapy } \\
\quad \Downarrow(\text { OR } 0.63) \\
\text { Costs } \Downarrow\end{array}$ \\
\hline Agus (2017) [25] & $\begin{array}{l}\text { Critically ill patients who were } \\
\text { receiving vasoactive support } \\
\text { for hypotension or invasive } \\
\text { mechanical ventilation }\end{array}$ & 713 & $0-17$ & 360 & $\begin{array}{l}3.7 \text { vs. } 0.3 \%(p=0.01 \\
\quad B G<2.2)\end{array}$ & $\begin{array}{l}\text { Infections } \Uparrow \\
\text { No differences: mortality, MOF, } \\
\text { mechanical ventilation }\end{array}$ \\
\hline
\end{tabular}

IIT: intensive insulin treatment; CTG: conventionally treated group; ICU: intensive care unit; BG: blood glucose; CRP: C-reactive protein; MOF: multiple organ failure; NE: not evaluated 
the incidence of GCS-induced HY with glycemia $>11.11$ $\mathrm{mmol} / \mathrm{L}(200 \mathrm{mg} / \mathrm{dL})$ is $12-50 \%$ [29]. A meta-analysis of 13 studies found that $32.3 \%$ of patients (range: $12-80$ years) developed GCS-induced HY and $18.6 \%$ of patients developed overt diabetes [30]. Odds ratios for the development of permanent diabetes after stopping GCS range from 1.36 to 2.31 [29].

Several studies have explored possible predictors of permanent diabetes after GCS therapy in adults, identifying factors including old age, overweight, previous glucose intolerance, family history of diabetes, race, the presence of specific human leukocyte antigens (HLA), and kidney transplantation [31]. Furthermore, new-onset diabetes in adults after GCS therapy has been correlated with the GCS dose and duration [28]. The pediatric literature on this topic is lacking, but it is reasonable to speculate that overweight and other risk factors for diabetes, such as ethnicity and family history, are likely predictors. In an analysis of children post-kidney transplantation, Prokai et al. reported that $29 \%$ presented with permanent derangement of glucose metabolism [32], frequently associated with overweight and positive family history of diabetes; in addition, hyperglycemic children were younger than those with normoglycemia.

\section{HY Induced}

\section{by Antineoplastic/Immunosuppressive Drugs}

HY occurs in approximately $10-30 \%$ of patients treated with antineoplastic drugs. Various antineoplastic agents, including cisplatin, everolimus, docetaxel, and androgen deprivation therapy, can contribute to uncontrolled HY [33•]. Hyperglycemic episodes that occur in children affected by acute lymphoblastic leukemia (ALL) are well known, and are treated with L-asparaginase and corticosteroids.

The reported incidence of transient HY among children treated for ALL varies between 4 and $27.5 \%$. Risk factors for developing HY in the course of ALL include age $>10$ years, increased body weight, family history of diabetes, and Down syndrome. Rarely, the onset of hyperglycemia can be acute, presenting as diabetic ketoacidosis or nonketotic hyperglycemic hyperosmolar syndrome. Insulin treatment is required in about $50 \%$ of cases [34]. In most cases, HY resolves with drug discontinuation. Despite its benign nature, transient HY has been associated with poorer survival of relapse, poor overall survival, and increased risk of developing metabolic disorders later in life $[34,35]$.

Tacrolimus is an immunosuppressive agent used to prevent and treat transplant rejection. Immunosuppressive therapy may be complicated by the development of HY, with the prevalence of diabetes after liver transplantation in adulthood ranging from 13.6 to $33 \%$. Di Cosmo et al. described the onset of symptomatic hyperglycemia without ketoacidosis in a 7-yearold boy undergoing liver transplantation due to Alagille syndrome. HY occurred during therapy with tacrolimus, required insulin treatment, and resolved when the immunosuppressive drug was discontinued. This case is interesting because the absence of ketoacidosis and the presence of normal Cpeptide levels during tacrolimus treatment indicate that betacell function was normal, arguing against beta-cell impairment previously ascribed to tacrolimus [36].

\section{Pathophysiology}

The overall effect of SHY in critical illness is to increase glycemia and provide a ready source of fuel for vital organs at a time of increased metabolic demand [2]. Whereas it may be adaptive and favor survival in the acute phase of critical illness, its persistence during the chronic phase may be harmful because of increased oxidative damage with potentiation of the proinflammatory response and impairment of coagulation pathways, cellular repair, and tissue healing.

SHY is determined both by increased gluconeogenesis and glycogenolysis and by insulin resistance due to an altered cellular uptake of glucose [37]. These mechanisms are a consequence of increased counter-regulatory hormones (i.e., epinephrine, norepinephrine, glucagon, cortisol, growth hormone $[\mathrm{GH}]$, and proinflammatory cytokines [TNF- $\alpha$, IL-1, IL-6]). Proinflammatory cytokines stimulate gluconeogenesis in the kidney and reduce insulin secretion by beta cells through $\alpha$ adrenergic receptors; increased GH and reduced insulin-like growth factor 1 (IGF-1) facilitate alanine release by the muscle in order to maintain liver gluconeogenesis.

In addition, counterregulatory hormones and proinflammatory cytokines promote both central (in liver) and peripheral (in muscle and adipose tissue) insulin resistance. Cortisol, $\mathrm{GH}$, and epinephrine reduce the translocation of the insulindependent glucose transporter protein 4 (GLUT-4) from internal membrane stores and reduce insulin binding; proinflammatory cytokines reduce cellular utilization of glucose via GLUT-4. In addition, catecholamines and GH stimulate lipolysis, causing the release of free fatty acids (FFA) and consequent increase in insulin resistance [38].

It is known that SHY is associated with more adverse consequences in critically ill patients than in healthy individuals and in diabetic patients. Sirinivisan et al. reported that hyperglycemia downregulates GLUT-1, GLUT-2, and GLUT-3, which are responsible for peripheral glucose uptake, in order to prevent cellular glucose overload [37]. In contrast, during critical illness, overexpression of these transporters leads to glucose overload and organ toxicity (endothelial, hepatic and immune cells, renal tubules, and gastrointestinal mucosa) [37]. Glucose overload results in excessive glycolysis and oxidative phosphorylation, with subsequent increased production of reactive oxygen species (ROS), causing mitochondrial dysfunction and altered energy metabolism. Ultimately, there is increased cellular apoptosis and, consequently, organ 
system failure. SH may also cause insufficient cellular autophagy, with worsening of cellular damage and delay of recovery from critical illness [37].

The pathophysiology of GCS includes some mechanisms previously described for SHY: increased gluconeogenesis and glycogenolysis and development of insulin resistance. In addition, GCS-induced HY may involve direct beta-cell damage: inhibition of insulin production and secretion and a proapoptotic effect on beta cells. These latter effects were studied among healthy 21-year-old volunteers [28].

\section{Management and Treatment}

HY induced by drugs ends at the discontinuation of the diabetogenic agent; however, there are common situations where it is not possible to discontinue the drug due to lack of alternatives and/or severity of the pathology that had required the drug. Since SHY is transient, it is unclear whether it must be treated and with which agents. In the case of severe clinical conditions (SHY1), the main reason for HY treatment is the high mortality rate. The controversial issue is whether to treat HY in non-lifethreatening conditions. In adults it has been common to treat $\mathrm{HY}$ with oral hypoglycemic agents and with insulin [39]. However, the evidence for the benefit of these treatments is not convincing, particularly in the pediatric age group. It is reasonable to consider only regular insulin or rapid-acting insulin analogs, sometimes in conjunction with long-acting insulin [40].

Some studies on children with SHY1 recommend treating HY for blood glucose levels $>11.11 \mathrm{mmol} / \mathrm{L}(200 \mathrm{mg} / \mathrm{dL})$, while other studies recommend initiation of insulin therapy for blood glucose $>8.33 \mathrm{mmol} / \mathrm{L}(150 \mathrm{mg} / \mathrm{dL}$ [1]. At this time, the decision seems to be completely arbitrary, although under severe conditions of SHY1, it is perhaps better to maintain tighter glycemic control. It is different in the case of SHY2, which has a limited health impact in terms of both severity and duration. At present, there are no evidence-based recommendations regarding HY treatment; however, after reviewing the literature, and based on our experience, it is reasonable to suggest the following:

- SHY1: treat with regular insulin, administered intravenously, for blood glucose values $\geq 8.33 \mathrm{mmol} / \mathrm{L}(150 \mathrm{mg} / \mathrm{dL})$;

- SHY2: treat if $H Y$ is $\geq 11.11 \mathrm{mmol} / \mathrm{L}(200 \mathrm{mg} / \mathrm{dL})$ and longer than $2 \mathrm{~h}$, using rapid-acting insulin analog at 0.1 $\mathrm{IU} / \mathrm{kg}$ in bolus via intravenous (IV) or subcutaneous (SC) administration.

- HY induced by drugs: discontinue causative medication whenever possible, and if blood glucose is $\geq 11.11$ $\mathrm{mmol} / \mathrm{L}(200 \mathrm{mg} / \mathrm{dL})$, treat with rapid-acting insulin ana$\log$ at $0.1-0.4 \mathrm{IU} / \mathrm{kg}$ via SC. In addition, HY induced by GCS could be treated at first with basal insulin (longacting insulin) in order to fight insulin resistance and normalize fasting blood glucose [40].
At the end of a short or long period of HY, as these children had an abnormal body response (HY) to a pathological condition, it is necessary to ask why the stress condition has induced HY. It is easy to think that a particular genotype leads to the HY response only in genetically predisposed individuals. Therefore, it may be necessary to explore the long-term prognosis of HY. It seems reasonable to propose an annual follow-up, with particular attention to patients with a family history of diabetes, in order to detect individuals predisposed to DM type 1 or 2 or those affected by monogenic DM (maturity-onset diabetes of the young [MODY] and ABCC8 mutations) [41], and also to prevent the development of obesity.

In conclusion, it is possible to propose four suggestions, which should be confirmed by further long-term studies: (1) HY aggravates severe conditions; it should not be underestimated, and it is often necessary to treat it. (2) In HY, treatment with only insulin can be justified. (3) In shortterm HY, treatment may not be necessary but it is never contraindicated. (4) Children with transient HY should be followed and periodically investigated for glucose metabolism derangement, both in the short and long term.

\section{Compliance with Ethical Standards}

Conflict of Interest Valentina Fattorusso, Rosa Nugnes, Alberto Casertano, Giuliana Valerio, Enza Mozzillo, and Adriana Franzese declare that they have no conflict of interest.

Human and Animal Rights and Informed Consent This article does not contain any studies with human or animal subjects performed by the any of the authors.

\section{References}

Papers of particular interest, published recently, have been highlighted as:

- Of importance

•• Of major importance

1. Srinivasan V, Spinella PC, Drott HR, et al. Association of timing, duration, and intensity of hyperglycemia with intensive care unit mortality in critically ill children. Pediatr Crit Care Med. 2004;5(4): 329-36.

2. Dungan KM, Braithwaite SS, Preiser JC. Stress hyperglycaemia. Lancet. 2009;373:1798-807.

3. Faustino EV, Apkon M. Persistent hyperglycemia in critically ill children. J Pediatr. 2005;146(1):30-4.

4. Wintergerst KA, Buckingham B, Gandrud L, et al. Association of hypoglycemia, hyperglycemia, and glucose variability with morbidity and death in the pediatric intensive care unit. Pediatrics. 2006;118(1):173-9.

5. Yung M, Wilkins B, Norton L, Slater A. Paediatric Study Group; Australian and New Zealand Intensive Care Society. Glucose control, organ failure, and mortality in pediatric intensive care. Pediatr Crit Care Med. 2008;9(2):147-52. https://doi.org/10.1097/PCC. 0b013e3181668c22. 
6. Hirshberg E, Larsen G, Van Duker H. Alterations in glucose homeostasis in the pediatric intensive care unit: Hyperglycemia and glucose variability are associated with increased mortality and morbidity. Pediatr Crit Care Med. 2008;9(4):361-6. https://doi.org/10. 1097/PCC.0b013e318172d401.

7. Preissig CM, Rigby MR. Pediatric critical illness hyperglycemia: risk factors associated with development and severity of hyperglycemia in critically ill children. J Pediatr. 2009;155(5):734-9. https:// doi.org/10.1016/j.jpeds.2009.05.007.

8. Ognibene KL, Vawdrey DK, Biagas KV. The association of age, illness severity, and glycemic status in a pediatric intensive care unit. Pediatr Crit Care Med. 2011;12(6):e386-90. https://doi.org/ 10.1097/PCC.0b013e3182192c53.

9. Gore DC, Chinkes D, Heggers J, et al. Association of hyperglycemia with increased mortality after severe burn injury. J Trauma. 2001;51(3):540-4.

10. Cochran A, Scaife ER, Hansen KW, et al. Hyperglycemia and outcomes from pediatric traumatic brain injury. J Trauma. 2003;55(6): 1035-8.

11. Branco RG, Garcia PC, Piva JP, et al. Glucose level and risk of mortality in pediatric septic shock. Pediatr Crit Care Med. 2005;6(4):470-2.

12. Yates AR, Dyke PC Taeed R, et al. Hyperglycemia is a marker for poor outcome in the postoperative pediatric cardiac patients. Pediatr Crit Care Med. 2006;7(4):351-5.

13. Day KM, Haub N, Betts H, et al. Hyperglycemia is associated with morbidity in critically ill children with meningococcal sepsis. Pediatr Crit Care Med. 2008;9(6):636-40. https://doi.org/10.1097/ PCC.0b013e31818d350b.

14.• Vanhorebeek GJ, Van den Berghe G. Critical Care Management of Stress-Induced Hyperglycemia. Current Diabetes Reports. 2018;18: 17. https://doi.org/10.1007/s11892-018-0988-2. This paper compares studies debating the efficacy and safety of tight glycemic control in critically ill patients and proposes strategies for safer glucose control.

15. Moradi S, Keshavarzi A, Tabatabaee SM. Is stress hyperglycemia a predicting factor of developing diabetes in future? Exp Clin Endocrinol Diabetes. 2015;123(10):614-6. https://doi.org/10. 1055/s-0035-1559719.

16. Valerio G, Franzese A, Carlin E, et al. High prevalence of stress hyperglycaemia in children with febrile seizures and traumatic injuries. Acta Paediatr. 2001;90(6):618-22.

17. Mobaireek KF, Alsheri A, Alsadoun A, Alsamari A, Alashhab A, Alrumaih $\mathrm{M}$, et al. Hyperglycemia in children hospitalized with acute asthma. Adv Exp Med Biol. 2018. https://doi.org/10.1007/ $55842018 \quad 152$

18. Weiss SL, Alexander J, Agus M. Extreme stress hyperglycemia during acute illness in a pediatric emergency department. Pediatr Emerg Care. 2010;26(9):626-32. https://doi.org/10.1097/PEC. 0b013e3181ef0488.

19. Vlasselaers D, Milants I, Desmet L. Intensive insulin therapy for patients in pediatric intensive care: a prospective, randomized controlled study. Lancet. 2009;373(9663):547-56. https://doi.org/10. 1016/S0140-6736(09)60044-1.

20. Agus MS, Steil GM, Wypij D, et al. Tight glycemic control versus standard care after pediatric cardiac surgery. N Engl J Med. 2012;367(13):1208-19.

21. Jeschke MG, Kraft R, Emdad F, et al. Glucose control in severely thermally injured pediatric patients: what glucose range should be the target? Ann Surg. 2010;252(3):521-7. https://doi.org/10.1097/ SLA.0b013e3181f2774c.

22. Srinivasan V, Agus MS. Tight glucose control in critically ill children - a systematic review and meta-analysis. Pediatr Diabetes. 2014;15(2):75-83.

23. Pham TN, Warren AJ, Phan $\mathrm{HH}$, et al. Impact of tight glycemic control in severely burned children. J Trauma. 2005;59(5):1148-54.
24. Macrae D, Grieve R, Allen E, et al. A randomized trial of hyperglycemic control in pediatric intensive care. N Engl J Med. 2014;370(2):107-18. https://doi.org/10.1056/NEJMoa1302564.

25. Agus MS, Wypij D, Hirshberg EL, et al. Tight Glycemic Control in Critically ill Children. N Engl J Med. 2017;376(8):729-41. https:// doi.org/10.1056/NEJMoa1612348.

26. Chikani UN, Ibekwe MU, Oguonu T, et al. Steroid-induced impairment of glucose tolerance: prevalence among pediatric patients on long-term steroid use in Nigeria. Pediatr Diabetes. 2017;18(8):9426. https://doi.org/10.1111/pedi.12514.

27. Tamez-Perez HE, Quintanilla-Flores DL, Rodriguez-Gutierrez R, et al. Steroid hyperglycemia: prevalence, early detection and therapeutic recommendations: a narrative review. World J Diabetes. 2015;6(8):1073-81. https://doi.org/10.4239/wjd.v6.i8.1073.

28. Van Raalte DH, Kwa KA, Van Genugten RE, et al. Islet-cell dysfunction induced by glucocorticoid treatment: potential role for altered sympathovagal balance? Metabolism. 2013;62(4):568-77. https://doi.org/10.1016/j.metabol.2012.10.007.

29. Donihi AC, Raval D, Saul M, et al. Prevalence and predictors of corticosteroid-related hyperglycemia in hospitalized patients. Endocr Pract. 2006;12(4):358-62.

30. Liu XX, Zhu XM, Miao Q, et al. Hyperglycemia induced by glucocorticoids in nondiabetic patients: a meta-analysis. Ann Nutr Metab. 2014;65(4):324-32. https://doi.org/10.1159/000365892.

31. Clore JN, Thurby-Hay L. Glucocorticoid-induced hyperglycemia. Endocr Pract. 2009;15(5):469-74. https://doi.org/10.4158/ EP08331.RAR.

32. Prokai A, Fekete A, Kis E, et al. Post-transplant diabetes mellitus in children following renal transplantation. Pediatr Transplant. 2008;12(6):643-9.

33. Arians G, De Jong S, Gietema J, et al. Cancer-drug induced insulin resistance: innocent bystander or unusual suspect. Cancer Treat Rev. 2015;41(4):376-84. https://doi.org/10.1016/j.ctrv.2015.02. 007. This paper discusses the pathogenesis of hyperglycemia induced by antineoplastic drugs and suggests treatment strategies.

34. Gatzioura I, Papakonstantinou E, Dimitriadou M, et al. Glucose Levels Before the Onset of Asparaginase Predicts Transient Hyperglycemia in Children with Acute Lymphoblastic Leukemia. Pediatr Blood Cancer. 2016;63:1181-4.

35. Yoshida H, Imamura T, Saito AM, et al. Protracted administration of 1-asparaginase in maintenance phase is the risk factor for hyperglycemia in older patients with pediatric acute lymphoblastic leukemia. PLoS One. 2015;10:e0136428.

36. Di Cosmo N, Vajiro P, Debray D, et al. Normal $\beta$-cell function in post-liver transplantation diabetes treated with tacrolimus. Diabetes Care. 2004;27(7):1837-8.

37. Srinivasan V. Stress Hyperglycemia in Pediatric Critical Illness: The Intensive Care Unit Adds to the Stress! J Diabetes Sci Technol. 2012;6(1):37-47. https://doi.org/10.1177/ 193229681200600106.

38. Preissig CM, Rigby MR. Hyperglycaemia results from beta-cell dysfunction in critically ill children with respiratory and cardiovascular failure: a prospective observational study. Crit Care. 2009;13(1):R27. https://doi.org/10.1186/cc7732.

39. Kwon S, Hermayer KL. Glucocorticoid-induced hyperglycemia. Am J Med Sci. 2013;345(4):274-7. https://doi.org/10.1097/MAJ. 0b013e31828a6a01.

40. Dhital SM, Shenker Y, Meredith M, et al. A retrospective study comparing neutral protamine Hagedorn insulin with glargine as basal therapy in prednisone-associated diabetes mellitus in hospitalized patients. Endocr Pract. 2012;18(5):712-9. https://doi.org/10. 4158/EP11371.OR.

41. Oron T, Gat-Yablonski G, Lazar L, et al. Stress hyperglycemia: a sign of familial diabetes in children. Pediatrics. 2011;128(6):e1614 7. https://doi.org/10.1542/peds.2010-3193. 